\title{
New treatment possibilities for patients with advanced coronary artery disease and critical limb ischemia - a feasibility study
}

\author{
Aleksander Żurakowski ${ }^{1,2}$, Magda Konkolewska ${ }^{1,2}$, Przemysław Nowakowski ${ }^{1}$, Paweł Buszman $^{1,2}$ \\ ${ }^{1}$ American Heart of Poland S.A., Malopolskie Heart and Vessels Center, Chrzanow, Poland \\ ${ }^{2}$ American Heart of Poland, Center for Cardiovascular Research and Development, Katowice, Poland
}

Adv Interv Cardiol 2016; 12, 4 (46): 368-371

DOI: 10.5114 /aic.2016.63639

Atherosclerosis can be limited to one vascular bed, but more often it takes a diffused form. Detection of the disease in one area should prompt further assessment of the patient for atherosclerotic disease in different territories. According to various studies, in patients over 50 years old with peripheral artery disease (PAD), critical limb ischemia (CLI) affects $1-2 \%$ of this population. These patients have very high risk of cardiovascular events due to concomitant coronary and cerebrovascular disease (5-year event rate of 20\%), and it has been proven that those events occur more frequently than ischemic events of the lower extremities, regardless of the stage of the lower extremity arterial disease (LEAD). Furthermore, over the 5 -year observation period, $75 \%$ of deaths are caused precisely by cardiovascular events [1].

Prevalence of coronary and carotid artery disease in patients with LEAD, as reported by various studies, is between $50 \%$ and $60 \%$. In the authors' registry of 218 patients with peripheral artery disease undergoing diagnostic coronary angiography, significant co-existing coronary artery disease was diagnosed in patients with LEAD or carotid artery disease in $63 \%$ and $65 \%$ respectively. It is interesting that $72 \%$ of those patients had never had any coronary artery disease (CAD) symptoms. Detection of concomitant CAD in patients with LEAD is especially important before planning the surgical strategy. Peripheral vascular surgery is considered a high-risk surgery, with the highest risk of cardiac complications (estimated 30-day cardiac event rates - cardiac death and myocardial infarction (MI) - of over 5\%) [2-9].

According to the above data, detailed cardiac evaluation of patients with LEAD undergoing vascular surgery should be performed routinely and become a standard of care.
Patients with CLI have worse prognoses than patients with different forms of malignant diseases and, as yet, no way has been found to improve these prognoses. Overall, mortality in patients with CLI approaches $50 \%$ at 5 years and $70 \%$ at 10 years [1]. Because of that, in our facility diagnostic peripheral angiography in patients with $C L I$ is followed by routine coronary angiography.

Our planned strategy for patients with $\mathrm{CLI}$ requiring immediate vascular surgery and diagnosed with advanced coronary artery disease (critical narrowing of main coronary artery) was hybrid treatment. The benefit of one-stage treatment is diminishing the risk of periprocedural cardiac complications in patients with peripheral arterial disease. The negative aspect of this approach is the high risk of early stent thrombosis during the vascular surgery, which activates coagulation and inflammation.

The investigated approach has been developed in the acute setting, following cardiological, surgical and anesthesiological consultation, to ensure the best results in patients with coexistence of LEAD in the form of CLI and CAD with critical stenosis of the coronary artery.

Some patients with $\mathrm{CLI}$ and a high cardiac risk profile hospitalized in Malopolskie Heart and Vessel Center in Chrzanow between 2013 and 2015 underwent simultaneous peripheral and coronary angiography. The patients' demographic and periprocedural data are shown in Table I. In 8 cases, critical stenosis of the coronary artery was observed and there was no possibility for endovascular treatment of the LEAD. Coronary artery stenosis was defined as significant on the basis of the visual inspection. In all patients the percentage diameter stenosis was over $90 \%$. In all cases there were no cardiac ischemic symptoms at rest and angina status was difficult to assess as patients had very low physical activity due to the CLI.

\section{Corresponding author:}

Magda Konkolewska MD, American Heart of Poland S.A., Malopolskie Heart and Vessels Center, 1 Topolowa St, 32-500 Chrzanow, Poland, phone: +48 3275869 00, e-mail: magda-kon@wp.pl

Received: 16.04.2016, accepted: 1.08.2016. 
Table I. Demographic and periprocedural data Parameter

Patient 1 Patient 2 Patient 3 Patient 4 Patient 5 Patient 6 Patient 7 Patient 8

\begin{tabular}{|c|c|c|c|c|c|c|c|c|}
\hline Age [years] & 81 & 56 & 57 & 63 & 72 & 66 & 49 & 79 \\
\hline Male/female & M & M & $\mathrm{F}$ & $\mathrm{F}$ & M & M & M & M \\
\hline Hypertension & $\checkmark$ & $\checkmark$ & $\checkmark$ & $\checkmark$ & $\checkmark$ & $\checkmark$ & $\checkmark$ & $\checkmark$ \\
\hline Smoker & $\checkmark$ & $\checkmark$ & $\checkmark$ & $\checkmark$ & - & - & $\checkmark$ & \\
\hline Hyperlipidemia & $\checkmark$ & $\checkmark$ & $\checkmark$ & $\checkmark$ & $\checkmark$ & $\checkmark$ & $\checkmark$ & $\checkmark$ \\
\hline Diabetes on tablets & - & $\checkmark$ & - & - & - & - & - & - \\
\hline Diabetes on insulin & - & - & $\checkmark$ & - & - & $\checkmark$ & - & - \\
\hline LVEF & $50 \%$ & $50 \%$ & $40 \%$ & $60 \%$ & $60 \%$ & $55 \%$ & $60 \%$ & $30 \%$ \\
\hline History of MI & - & $\checkmark$ & - & $\checkmark$ & - & - & $\checkmark$ & $\checkmark$ \\
\hline History of $\mathrm{PCl}$ & - & - & - & - & - & - & $\checkmark$ & - \\
\hline Lee index & 1 & 1 & 2 & 1 & 1 & 1 & 2 & 3 \\
\hline NSQIP risk of any complications & $16 \%$ & $20 \%$ & $15 \%$ & $14 \%$ & $13 \%$ & $23 \%$ & $14 \%$ & $21 \%$ \\
\hline NSQIP risk of any complications & $21 \%$ & $29 \%$ & $19 \%$ & $18 \%$ & $20 \%$ & $26 \%$ & $24 \%$ & $32 \%$ \\
\hline Syntax score & 5 & 7 & 7 & 5 & 2 & 15 & 2 & 3 \\
\hline Access site used for $\mathrm{PCl}$ & Femoral & Femoral & Radial & Femoral & Femoral & Radial & Radial & Femoral \\
\hline Atrial fibrillation & - & - & $\checkmark$ & - & - & - & - & $\checkmark$ \\
\hline Need for oral anticoagulation & - & - & $\checkmark$ & - & - & - & - & $\checkmark$ \\
\hline Hemoglobin level before procedure $[\mathrm{g} / \mathrm{dl}]$ & 10.3 & 16.8 & 14.4 & 14.1 & 15.8 & 12.2 & 12.4 & 14.2 \\
\hline Hemoglobin level after procedure [g/dl] & 9.8 & 12.4 & 11.2 & 13.2 & 12.4 & 9.9 & 10.1 & 11.1 \\
\hline GFR before procedure $\left[\mathrm{ml} / \mathrm{min} / 1.73 \mathrm{~m}^{2}\right]$ & 65.4 & 93.5 & 63.6 & 64.9 & 88.2 & 81.3 & 59.7 & 48.2 \\
\hline GFR after procedure $\left[\mathrm{ml} / \mathrm{min} / 1.73 \mathrm{~m}^{2}\right]$ & 52.1 & 96.3 & 75.8 & 80.6 & 117.6 & 140.3 & 112.3 & 47.4 \\
\hline
\end{tabular}

$L V E F$ - left ventricular ejection fraction, $M I$ - myocardial infarction, $P C l$ - percutaneous coronary intervention.

Vascular surgery had to be performed without any delay to prevent limb loss. Despite the fact that the main complaint reported by patients was leg pain at rest, we decided, according to the coronary artery anatomy, to perform percutaneous revascularization with stent implantation. P2Y12 inhibitor loading dose administration was delayed to decrease bleeding risk during vascular surgery. All patients were given a loading dose of aspirin (if not on chronic aspirin therapy). After uncomplicated percutaneous coronary intervention $(\mathrm{PCl})$, patients were transferred for vascular surgery to a theater equipped with a mobile angiograph with optional monitoring of the outcome with angiography. During the $\mathrm{PCl}$, mean fluoroscopy time was 7 min $12 \mathrm{~s}$, mean contrast media load was $160 \mathrm{ml}$ and mean radiation exposure reached $652.8 \mathrm{mGy} /$ patient. Each patient underwent major vascular surgery: 7 cases of bypass grafting, 1 bypass thrombectomy, 1 endarterectomy and 1 endarterectomy with patch angioplasty. Additionally, 4 cases were combined with peripheral angioplasty (Table II). For the $\mathrm{PCl}$, a standard, weight-adjusted $(100 \mathrm{U} / \mathrm{kg}$ ) dose of unfractionated heparin (UFH) was administered (mean dose per patient was $7000 \mathrm{U}$ ). At the beginning of the vascular surgery each patient was given an additional UFH dose, and it was $1200 \mathrm{U}$ on average.

Mean time from the end of the $\mathrm{PCl}$ to the beginning of the vascular surgery was $75 \mathrm{~min}$, and mean time from the end of the $\mathrm{PCl}$ to administration of the loading dose of P2Y12 inhibitor (600 mg of clopidogrel) was $190 \mathrm{~min}$.

The postoperative course was stable with no coronary or peripheral ischemic symptoms. No acute kidney injury was observed. Despite delayed P2Y12 loading dose administration, there were no stent thrombosis events. We did not observe any bleeding related to the $\mathrm{PCl}$. Perioperative bleeding assessment was conducted with a grading scale from A to D: A - minimal bleeding; B - controllable bleeding - did not affect the surgery as planned; C - increased bleeding - affecting surgery but not jeopardizing its planned outcome; D - extreme bleeding - did not allow for the procedure to be completed as planned.

All patients received $B$ and the drainage volume was $600 \mathrm{ml}$ on average. No blood transfusion was required. 
Table II. Procedures performed in patients

\begin{tabular}{|c|c|c|c|c|}
\hline Patient & Peripheral angiography & Coronary angiography & $\mathrm{PCl}$ & Vascular surgery \\
\hline 1 & $\begin{array}{l}\text { Right common iliac artery } \\
\text { occlusion }\end{array}$ & Critical stenosis of LCX & $\begin{array}{l}\text { LCX with } 3.5 \times 25 \mathrm{~mm} \mathrm{BMS} \\
\text { implantation }\end{array}$ & $\begin{array}{c}\text { Left to right femorofemoral } \\
\text { bypass grafting (external } \\
\text { iliac artery to right superficial } \\
\text { femoral artery) }\end{array}$ \\
\hline 2 & Left bypass graft occlusion & $\begin{array}{l}\text { Critical stenosis of LAD. } \\
\text { CTO of RCA. } \\
\text { 80\% stenosis of first diagonal } \\
\text { artery }\end{array}$ & $\begin{array}{l}\text { LAD with } 2.5 \times 15 \mathrm{~mm} \text { DES } \\
\text { implantation }\end{array}$ & $\begin{array}{l}\text { Left distal fem-pop bypass } \\
\text { thrombectomy. } \\
\text { Balloon angioplasty of ante- } \\
\text { rior tibial artery and distal } \\
\text { bypass anastomosis. } \\
\text { Revision of dorsalis pedis } \\
\text { artery }\end{array}$ \\
\hline 3 & $\begin{array}{l}\text { Left common femoral artery } \\
\text { occlusion }\end{array}$ & Critical stenosis of RCA & $\begin{array}{l}\text { RCA with } 3.0 \times 33 \mathrm{~mm} \\
\text { DES implantation }\end{array}$ & Left iliofemoral bypass \\
\hline 4 & $\begin{array}{l}\text { Right superficial femoral } \\
\text { artery occlusion }\end{array}$ & $\begin{array}{l}\text { Critical stenosis of RCA. } \\
70 \% \text { stenosis of first OM } \\
\text { branch }\end{array}$ & $\begin{array}{l}\text { RCA with } 3.0 \times 48 \mathrm{~mm} \\
\text { DES implantation }\end{array}$ & $\begin{array}{l}\text { Right fem-pop bypass. } \\
\text { PTA of right popliteal artery } \\
\text { and tibioperoneal trunk }\end{array}$ \\
\hline 5 & $\begin{array}{l}\text { Right external iliac artery } \\
\text { in-stent stenosis, right common } \\
\text { femoral artery stenosis, bilateral } \\
\text { femoro-popliteal } \\
\text { occlusion }\end{array}$ & Critical stenosis of RCA & $\begin{array}{l}\text { RCA with } 2.75 \times 14 \mathrm{~mm} \\
\text { DES implantation }\end{array}$ & $\begin{array}{l}\text { Right fem-pop bypass. } \\
\text { PTA of right external iliac } \\
\text { artery }\end{array}$ \\
\hline 6 & $\begin{array}{l}\text { Left superficial femoral artery } \\
\text { occlusion }\end{array}$ & $\begin{array}{l}\text { Critical stenosis of RCA. } \\
\text { Critical stenosis of LAD }\end{array}$ & $\begin{array}{l}\text { RCA with } 2.75 \times 22 \mathrm{~mm} \\
\text { DES implantation. } \\
\text { LAD with } 2.75 \times 15 \mathrm{~mm} \text {, } \\
2.75 \times 9 \mathrm{~mm}, 3.5 \times 12 \mathrm{~mm} \\
3 \times \text { DES implantation }\end{array}$ & $\begin{array}{l}\text { Endarterectomy of left } \\
\text { common femoral artery with } \\
\text { patch angioplasty. } \\
\text { PTA of left superficial femoral } \\
\text { artery with stent implantation }\end{array}$ \\
\hline 7 & $\begin{array}{l}\text { Right femoro-popliteal } \\
\text { occlusion }\end{array}$ & Critical stenosis of RCA & $\begin{array}{l}\text { RCA with } 2.75 \times 18 \mathrm{~mm} \\
\text { DES implantation }\end{array}$ & $\begin{array}{l}\text { Right fem-pop bypass hallux } \\
\text { amputation }\end{array}$ \\
\hline 8 & $\begin{array}{l}\text { Left deep femoral artery } \\
\text { stenosis }\end{array}$ & Critical stenosis of RCA & $\begin{array}{l}\text { RCA with } 3.5 \times 15 \mathrm{~mm} \\
\text { DES implantation }\end{array}$ & $\begin{array}{l}\text { Revision and endarterectomy } \\
\text { of left deep femoral artery }\end{array}$ \\
\hline
\end{tabular}

$R C A$ - right coronary artery, $L C X$ - left circumflex artery, $L A D$ - left anterior descending artery, OM - obtuse marginal, PTA - percutaneous transluminal angioplasty, CTO - chronic total occlusion, BMS - bare metal stent, DES - drug-eluting stent.

During hospitalization, limb perfusion improvement was observed and the rest pain subsided. In the 30-day and 3-month follow-ups no cardiac events were observed.

The hybrid approach has emerged as a new, secure model of management. The new techniques have been developed by a number of specialists to ensure greater safety for patients and better early and long-term results. They are still evolving, and we believe that in the near future they will become a routine method of treatment. In most cases, in patients with LEAD, the assessment of CAD severity is difficult due to the very low patient physical activity. Cardiac stress test on a treadmill or bicycle for the purpose of CAD diagnoses in patients with $\mathrm{CLI}$ is frequently impossible. Stress echocardiography as a good diagnostic tool has its limitations. In contrast to stress tests, coronary angiography gives us an exact picture of the coronary anatomy and allows us to plan a possible treatment strategy ( $\mathrm{PCl} /$ coronary artery by-

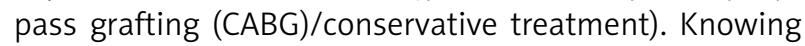
the CAD severity, we can plan treatment, minimizing cardiac complication rates after vascular surgery and improve the patients' long-term prognosis. According to the
ESC Clinical Practice Guidelines on Pre-operative Cardiac Risk Assessment and Perioperative Cardiac Management in Non-Cardiac Surgery from 2009 [4], pre-operative angiography may be considered in cardiac-stable patients undergoing high-risk surgery with class of recommendation IIb and level of evidence B.

Several clinical trials demonstrated good results of CABG or PCI before vascular surgery. In 1992 Kenneth et al. performed 54 non-cardiac operations in 50 patients at a median 9 days after PCI. In 1998 Gottlieb et al. published results of 194 patients who had undergone aortic abdominal surgery, carotid endarterectomy (CEA) or peripheral vascular surgery preceded by $\mathrm{PCI}$ up to 18 months. In both cases the incidence of perioperative cardiac morbidity was low and the procedures were considered safe $[5,6]$.

Because there are no detailed data available on how to approach patients qualified for vascular surgery with diagnosed CLI and severe coronary artery stenosis, our preliminary results suggest that the hybrid coronary-peripheral approach with cooperation between interventional cardiologists and vascular surgeons is possible and might be a good therapeutic option. 
Whilst performing peripheral angiography, when we are able to expand the procedure with coronary angiography, we do not significantly delay the surgical intervention, and additionally we obtain a detailed anatomy of coronary arteries. It allows us to diagnose CAD in patients who, because of CLI, are usually CAD asymptomatic (extremely low physical activity). It also allows us to predict possible adverse events and prevent their occurrence.

Although the risk of stent thrombosis (ST) while on dual antiplatelet therapy (DAPT) is low $(<2 \%)$, if it occurs, the mortality rate reaches $7-25 \%[7,8]$. There are no data available on the ST risk when DAPT is postponed due to vascular surgery which activates coagulation and inflammatory processes. However, we did not observe any incidents of ST - our study group is too small to conclude that this approach does not increase the risk of early ST.

To the best of our knowledge, this is the first report on the hybrid approach in patients with $\mathrm{CLI}$ and advanced CAD.

The results of our study indicate that the hybrid procedure of coronary stenting and vascular surgery may be a good therapeutic option. Further extended studies will need to be carried out in order to fully assess its real value. Regardless of the mentioned limitations, such a hybrid approach could be the only treatment option in some patients with concomitant CLI and CAD.

\section{Conflict of interest}

The authors report no conflict of interest.

\section{References}

1. Norgren L, Hiatt WR, Dormandy JA, et al. Inter-Society Consensus for the Management of Peripheral Arterial Disease (TASC II). J Vasc Surg 2007; 45: S5-67.

2. Boersma E, Kertai MD, Schouten O, et al. Perioperative cardiovascular mortality in noncardiac surgery: validation of the Lee cardiac risk index. Am J Med 2005; 118: 1134-41.

3. Wirthlin DJ, Cambria RP. Surgery-specific considerations in the cardiac patient undergoing noncardiac surgery. Prog Cardiovasc Dis 1998; 40: 453-68.

4. Poldermans D, Bax JJ, Boersma E, et al. Guidelines for pre-operative cardiac risk assessment and perioperative cardiac management in non-cardiac surgery. Eur Heart J 2009; 30: 2769-812.

5. Huber KC, Evans MA, Bresnahan JF, et al. Outcome of noncardiac operations in patients with severe coronary artery disease successfully treated preoperatively with coronary angioplasty. Mayo Clin Proc 1992; 67: 15-21.

6. Gottlieb A, Banoub M, Sprung J, et al. Perioperative cardiovascular morbidity in patients with coronary artery disease undergoing vascular surgery after percutaneous transluminal coronary angioplasty. J Cardiothorac Vasc Anesth 1998; 12: 501-6.

7. Schomig A, Kastrati A, Mudra H, et al. Four-year experience with Palmaz-Schatz stenting in coronary angioplasty complicated by dissection with threatened or present vessel closure. Circulation 1994; 90: 2716-24.
8. Leon MB, Baim DS, Popma JJ, et al. A clinical trial comparing three antithrombotic-drug regimens after coronary-artery stenting. N Engl J Med 1998; 339: 1665-71.

9. Kristensen SD, Knuuti J, Saraste A, et al.; Authors Task Force Members. 2014 ESC/ ESA Guidelines on non-cardiac surgery: cardiovascular assessment and management: The Joint Task Force on noncardiac surgery: cardiovascular assessment and management of the European Society of Cardiology (ESC) and the European Society of Anaesthesiology (ESA). Eur Heart J 2014; 35: 2383-431. 